\title{
Estimation of Maneuverability of Fishing Vessel Considering Hull-Form Characteristics
}

\author{
Su-Hyung Kim ${ }^{1} \mathbb{1}$, Chun-Ki Lee ${ }^{2, *}$ and Sang-Min Lee ${ }^{3}$ \\ 1 Training Ship, Pukyong National University, Busan 48513, Korea; prodoll1@naver.com \\ 2 Division of Navigation Convergence Studies, Korea Maritime and Ocean University, Busan 49112, Korea \\ 3 Division of Marine Industry Transportation Science and Technology, Kunsan National University, \\ Jeonbuk 54150, Korea; smlee@kunsan.ac.kr \\ * Correspondence: leeck@kmou.ac.kr
}

check for updates

Citation: Kim, S.-H.; Lee, C.-K.; Lee, S.-M. Estimation of Maneuverability of Fishing Vessel Considering Hull-Form Characteristics. J. Mar. Sci. Eng. 2021, 9, 569. https://doi.org/ $10.3390 /$ jmse 9060569

Received: 17 April 2021

Accepted: 22 May 2021

Published: 25 May 2021

Publisher's Note: MDPI stays neutral with regard to jurisdictional claims in published maps and institutional affiliations.

Copyright: (c) 2021 by the authors. Licensee MDPI, Basel, Switzerland. This article is an open access article distributed under the terms and conditions of the Creative Commons Attribution (CC BY) license (https:/ / creativecommons.org/licenses/by/ $4.0 /)$.

\begin{abstract}
Fishing vessels with a length $\left(\mathrm{L}_{\mathrm{BP}}\right)$ of less than $100 \mathrm{~m}$ are generally not required to comply with the mandatory IMO Ship Maneuverability Standards. Therefore, an analytical method using empirical formula is preferred rather than a model test, which consumes a lot of time and monetary resources in estimating the maneuverability at the design stage. However, most empirical formulas have been derived from the model test results of merchant ships, and in the process, estimation errors may occur when hull-form parameters ( $\mathrm{L} / \mathrm{B}$ or $\mathrm{C}_{\mathrm{b}} \mathrm{B} / \mathrm{L}$ ) with high correlation are applied to fishing vessel hull form whose characteristics are different from those of merchant ships. Therefore, a modified empirical formula was derived from previous research by including major parameters of fishing vessel hull form in the Kijima 90 empirical formula. In this study, maneuverability of stern trawler hull form is estimated for validating a modified empirical formula. The study confirmed that including characteristic parameters of the fishing vessel hull form in the empirical formula developed for merchant ships could improve the accuracy of estimation.
\end{abstract}

Keywords: maneuverability; modified empirical formula; parameters of fishing vessel; stern trawler

\section{Introduction}

The IMO (International Maritime Organization) held the 137th MSC (Maritime Safety Committee) in 2002, which finalized the ship maneuverability standards to be applicable to powered vessels built after 1 January 2004. These vessels should have a rudder and propeller, the length $\left(\mathrm{L}_{\mathrm{BP}}\right)$ of $100 \mathrm{~m}$ or over, and includes all chemical tankers and gas carriers irrespective of length [1]. Therefore, when IMO ship maneuverability standards cannot be met, hull form modifications and repairs will require time and money, so research to estimate the ship maneuverability from the design stage has become active.

On the other hand, research on estimating maneuverability of vessels during the design stage focuses mainly on merchant ship hull form, whereas research in fishing vessel hull form is lacking. Most of the studies on the maneuverability of fishing vessels have been conducted on real vessels, such as evaluating the maneuverability for collision and stranding situations [2], analyzing the characteristics of turning-motion in narrow areas [3], analyzing the maneuverability of fisheries training vessels [4-6] using the methods similar to the above. However, it is difficult to find the studies that estimated and analyzed the maneuverability of fishing vessels from the design stage, and representatively, there are some studies by Yoshimura et al. [7,8] and Dan et al. [9].

A typical reason is that there are not many large fishing vessels with a length $\left(\mathrm{L}_{\mathrm{BP}}\right)$ of $100 \mathrm{~m}$ or more, to which maneuverability standards can be applied. Furthermore, it is not mandatory for the ship company to conduct costly and time-consuming model tests for ship lines. For this reason, at the fishing vessel design stage, the use of the analytical method using empirical formulas which can estimate maneuverability can be applied. This can save time and money. 
However, empirical formulas were derived from the process of regression analysis of the model test results of the merchant ship. When applying these formulas to fishing vessels with different hull-form characteristics, estimation errors may occur due to differences in hull-form parameters, such as L/B or $\mathrm{C}_{b} \mathrm{~B} / \mathrm{L}$ [10]. Nevertheless, the fishing industry involves multiple people being aboard the vessels, and in case of any accidents related to the maneuvering of the fishing vessel, such as collision or stranding, these can prove fatal [11-14]. To overcome such a situation, estimation is required at the design stage along with maneuvering motion simulating models which consider maneuvering characteristics. Therefore, the authors used the Kijima 90 empirical formula [15], which is well known to researchers, in previous studies, to estimate the maneuverability of fishing vessels, and analyzed the error generated quantitatively and qualitatively [16-18]. In addition, in order to reduce the errors occurring in the estimation process, the modified empirical formula was derived by including the hull-form parameters of five stern trawlers in the process of deriving the Kijima 90 empirical formula [15].

In this study, to validate the modified empirical formula, a study was conducted to estimate the maneuverability of $85 \mathrm{~m}$-long $\left(\mathrm{L}_{\mathrm{BP}}\right)$ stern trawler launched in October 2020, and a method is presented to improve the accuracy of estimating the maneuverability.

\section{Mathematical Model \& Empirical Formula}

\subsection{Mathematical MODEL}

\subsubsection{Coordinate System and Equation of Maneuvering Motion}

The right-hand orthogonal coordinate system was used to represent the maneuvering motion of a vessel along with a fixed-hull coordinate system $(\mathrm{o}-\mathrm{xyz})$, which has the midship of the hull fixed at the origin (o) on the earth-fixed coordinate system $\left(\mathrm{o}_{0}-\mathrm{x}_{0} \mathrm{y}_{0} \mathrm{z}_{0}\right)$ (Figure 1). At this time, the maneuvering motion equation is non-dimensionalized and represented as Equation (6), and the Kijima 90 empirical formula is represented by the drift angle $\beta$ and the non-dimensionalized angular velocity $\mathrm{r}$.

$$
\begin{aligned}
& \left(\mathrm{m}^{\prime}+\mathrm{m}_{\mathrm{x}}^{\prime}\right)\left(\frac{\mathrm{L}}{\mathrm{U}}\right)\left(\frac{\dot{\mathrm{U}}}{\mathrm{U}} \cos \beta-\dot{\beta} \sin \beta\right)+\left(\mathrm{m}^{\prime}+\mathrm{m}_{\mathrm{y}}^{\prime}\right) \mathrm{r} / \sin \beta=\mathrm{X} \prime
\end{aligned}
$$

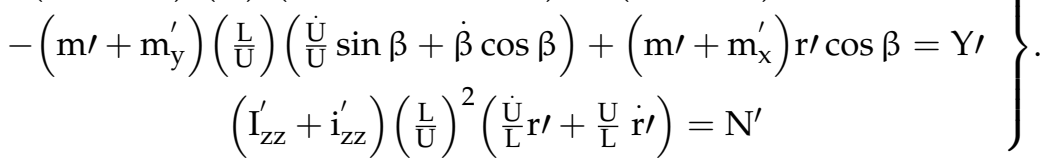

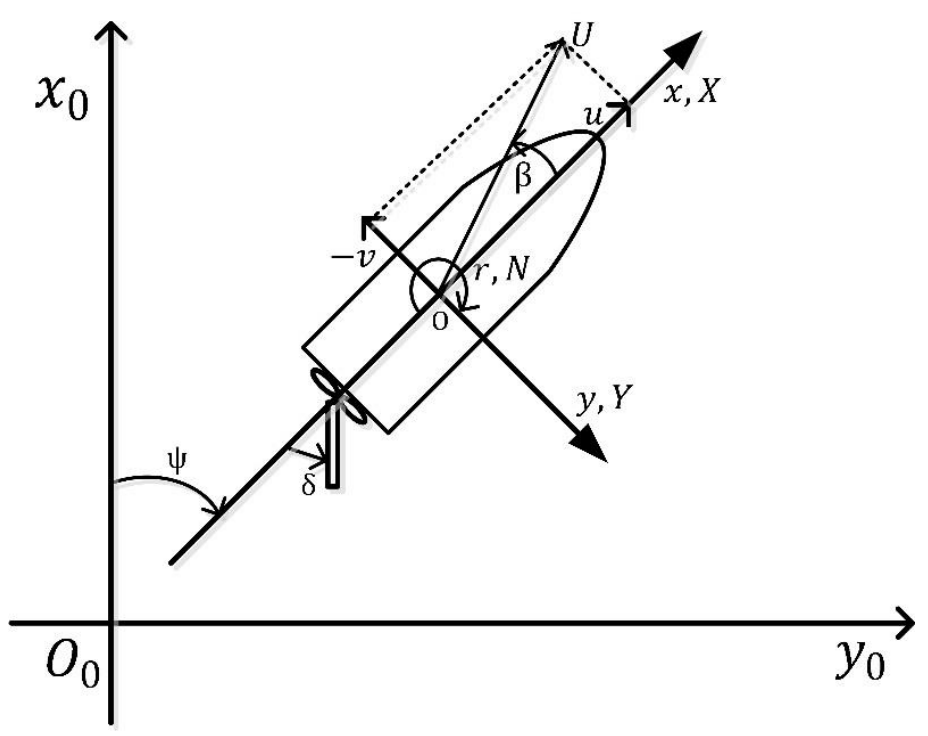

Figure 1. Coordinate System for Maneuvering Motion. 
The Kijima 90 empirical formula was based on the MMG (Maneuvering Modeling Group) model $[19,20]$, and the external force terms $X^{\prime}, Y^{\prime}$ and $N^{\prime}$ on the right side of Equation (1) can be divided into hull-, rudder-, and propeller-components, as shown in Equation (2) where the subscripts, H, R, and P represent hull, rudder, and propeller, respectively [15].

$$
\left.\begin{array}{c}
X^{\prime}=X_{H}^{\prime}+X_{R}^{\prime}+X_{P}^{\prime} \\
Y^{\prime}=Y_{H}^{\prime}+Y_{R}^{\prime} \\
N^{\prime}=N_{H}^{\prime}+N_{R}^{\prime}
\end{array}\right\}
$$

\subsubsection{Forces and Moment acting on a Hull}

The forces acting on the hull $\mathrm{X}_{\mathrm{H}}^{\prime}, \mathrm{Y}_{\mathrm{H}}^{\prime}$ and Moment $\mathrm{N}_{\mathrm{H}}^{\prime}$ can be represented as shown in Equation (3) using the drift angle $\beta$ and the non-dimensionalized angular velocity $\mathrm{r}^{\prime}$ [21].

$$
\left.\begin{array}{c}
\mathrm{X}_{\mathrm{H}}^{\prime}=\mathrm{X}_{\beta \mathrm{r}}^{\prime} \mathrm{r} / \sin \beta+\mathrm{X}_{\mathrm{uu}}^{\prime} \cos ^{2} \beta \\
\mathrm{Y}_{\mathrm{H}}^{\prime}=\mathrm{Y}_{\beta}^{\prime} \beta+\mathrm{Y}_{\mathrm{r}}^{\prime} \mathrm{r}^{\prime}+\mathrm{Y}_{\beta \beta}^{\prime} \beta|\beta|+\mathrm{Y}_{\mathrm{rr}}^{\prime} \mathrm{r}^{\prime}|\mathrm{r} \prime|+\left(\mathrm{Y}_{\beta \beta \mathrm{r}}^{\prime} \beta+\mathrm{Y}_{\beta \mathrm{rr}}^{\prime} \mathrm{r}^{\prime}\right) \beta \mathrm{r} \prime \\
\mathrm{N}_{\mathrm{H}}^{\prime}=\mathrm{N}_{\beta}^{\prime} \beta+\mathrm{N}_{\mathrm{r}}^{\prime} \mathrm{r} \prime+\mathrm{N}_{\beta \beta}^{\prime} \beta|\beta|+\mathrm{N}_{\mathrm{rr}}^{\prime} \mathrm{r}^{\prime}|\mathrm{r} \prime|+\left(\mathrm{N}_{\beta \beta \mathrm{r}}^{\prime} \beta+\mathrm{N}_{\beta \mathrm{rr}}^{\prime} \mathrm{r}^{\prime}\right) \beta \mathrm{r}{ }^{\prime}
\end{array}\right\}
$$

2.1.3. Forces and Moment Generating from a Propeller

Generally, the force acting on propellers is mainly forward-backward force $X_{P}^{\prime}$, and if right-left force $Y_{P}^{\prime}$ and Moment $N_{P}^{\prime}$ are omitted based on the assumption that they are small [15], the force can be represented as shown in Equation (4):

$$
\left.\begin{array}{c}
\mathrm{X}_{\mathrm{P}}^{\prime}=\mathrm{C}_{\mathrm{tP}}\left(1-\mathrm{t}_{\mathrm{P} 0}\right) \mathrm{K}_{\mathrm{T}}\left(\mathrm{J}_{\mathrm{P}}\right) \mathrm{n}^{2} \mathrm{D}_{\mathrm{P}}^{4} / \frac{1}{2} \mathrm{LdU}^{2} \\
\mathrm{~K}_{\mathrm{T}}\left(\mathrm{J}_{\mathrm{P}}\right)=\mathrm{C}_{1}+\mathrm{C}_{2} \mathrm{~J}_{\mathrm{P}}+\mathrm{C}_{3} \mathrm{~J}_{\mathrm{P}}^{2} \\
\mathrm{~J}_{\mathrm{P}}=\mathrm{U} \cos \beta\left(1-\mathrm{w}_{\mathrm{P}}\right) /\left(\mathrm{nD}_{\mathrm{P}}\right)
\end{array}\right\}
$$

\subsubsection{Forces and Moment Generating from a Rudder}

Force $X_{R}^{\prime}, Y_{R}^{\prime}$ and Moment $N_{R}^{\prime}$ acting on a rudder can be expressed as shown in Equation (5) where $t_{R}, a_{H}$ and $x_{H}^{\prime}$ are the main interaction coefficients between the rudders, propellers, and hulls, and a non-dimensionalized normal force acting on the rudder $\mathrm{F}_{\mathrm{N}}^{\prime}$ is also highly correlated with the interaction coefficients [15].

$$
\left.\begin{array}{c}
\mathrm{X}_{\mathrm{R}}^{\prime}=-\left(1-\mathrm{t}_{\mathrm{R}}\right) \mathrm{F}_{\mathrm{N}}^{\prime} \sin \delta \\
\mathrm{Y}_{\mathrm{R}}^{\prime}=-\left(1+\mathrm{a}_{\mathrm{H}}\right) \mathrm{F}_{\mathrm{N}}^{\prime} \cos \delta \\
\mathrm{N}_{\mathrm{R}}^{\prime}=-\left(\mathrm{x}_{\mathrm{R}}^{\prime}+\mathrm{a}_{\mathrm{H}} \mathrm{x}_{\mathrm{H}}^{\prime}\right) \mathrm{F}_{\mathrm{N}}^{\prime} \cos \delta
\end{array}\right\}
$$

where, the normal force acting on the rudder $\mathrm{F}_{\mathrm{N}}$, which is highly correlated with the interaction coefficients, can be represented as in Equation (6) after being non-dimensionalized.

$$
\begin{gathered}
\mathrm{F}_{\mathrm{N}}^{\prime}=\left(\mathrm{A}_{\mathrm{R}} / \mathrm{LD}\right) \mathrm{C}_{\mathrm{N}} \mathrm{U}_{\mathrm{R}}^{\prime 2} \operatorname{sina} \mathrm{R}_{\mathrm{R}} \\
\mathrm{C}_{\mathrm{N}}=6.13 \mathrm{~K}_{\mathrm{R}} /\left(\mathrm{K}_{\mathrm{R}}+2.25\right) \\
\mathrm{U}_{\mathrm{R}}^{\prime 2}=\left(1-\mathrm{w}_{\mathrm{R}}\right)^{2}\{1+\mathrm{Cg}(\mathrm{s})\} \\
\mathrm{g}(\mathrm{s})=\eta \mathrm{K}\{2-(2-\mathrm{K}) \mathrm{s}\} \mathrm{s} /(1-\mathrm{s})^{2} \\
\eta=\mathrm{D}_{\mathrm{P}} / \mathrm{h}_{\mathrm{R}} \\
\mathrm{K}=0.6\left(1-\mathrm{w}_{\mathrm{P}}\right) /\left(1-\mathrm{w}_{\mathrm{R}}\right) \\
\mathrm{s}=1.0-\left(1-\mathrm{w}_{\mathrm{P}}\right) \mathrm{U} \cos \beta / \mathrm{nP} \\
\mathrm{w}_{\mathrm{R}}=\mathrm{w}_{\mathrm{R} 0} \cdot \mathrm{w}_{\mathrm{P}} / \mathrm{w}_{\mathrm{P} 0} \\
\mathrm{a}_{\mathrm{R}}=\delta-\gamma \cdot \beta_{\mathrm{R}}^{\prime} \\
\beta_{\mathrm{R}}^{\prime}=\beta-2 \mathrm{x}_{\mathrm{R}}^{\prime} \cdot \mathrm{r} /, \mathrm{x}_{\mathrm{R}}^{\prime} \cong-0.5
\end{gathered}
$$




\subsection{Kijima 90 Empirical Formula}

The reference model used to derive the modified empirical formula is the Kijima 90 empirical formula. This is because the specifications of the vessel used in the process of deriving the empirical formula and the model test are openly available to the public and are divided into two types depending on whether the stern shape provides more selection $[15,22,23]$. However, based on the previous studies, the Kijima 90 empirical formula [15], which did not take into account the stern shape, was deemed more appropriate for estimating the maneuverability of fishing vessels with characteristics that differ from those of merchant ships.

The Kijima 90 empirical formula was derived from the results of 13 model test regression analyses, which included oil tankers, general cargo ships, car carriers, and RORO. An equation to derive the coefficients acting on a hull with an even keel and the interaction coefficients acting between hulls, propellers, and rudders may be expressed as shown in Equation (7):

$$
\begin{gathered}
\mathrm{Y}_{\beta}^{\prime}=\frac{1}{2} \pi k+\frac{1.4 \mathrm{C}_{\mathrm{b}} \mathrm{B}}{\mathrm{L}} \\
\mathrm{Y}_{\beta \beta}^{\prime}=\frac{2.5 \mathrm{~d}\left(1-\mathrm{C}_{\mathrm{b}}\right)}{\mathrm{B}}+0.5 \\
\mathrm{Y}_{\mathrm{r}}^{\prime}-\left(\mathrm{m} /+\mathrm{m}_{\mathrm{x}}^{\prime}\right)=-\frac{1.5 \mathrm{C}_{\mathrm{b}} \mathrm{B}}{\mathrm{L}} \\
\mathrm{Y}_{\mathrm{rr}}^{\prime}=\frac{0.343 \mathrm{~d} \mathrm{C}_{\mathrm{b}}}{\mathrm{B}}-0.07 \\
\mathrm{Y}_{\beta \mathrm{rr}}^{\prime}=\frac{5.95 \mathrm{~d}\left(1-\mathrm{C}_{\mathrm{b}}\right)}{\mathrm{B}} \\
\mathrm{Y}_{\beta \beta \mathrm{r}}^{\prime}=\frac{1.5 \mathrm{~d} \mathrm{C}_{\mathrm{b}}}{\mathrm{B}}-0.65 \\
\mathrm{~N}_{\beta}^{\prime}=\mathrm{k} \\
\mathrm{N}_{\beta \beta}^{\prime}=-\frac{0.96 \mathrm{~d}\left(1-\mathrm{C}_{\mathrm{b}}\right)}{\mathrm{B}}+0.066 \\
\mathrm{~N}_{\mathrm{r}}^{\prime}=-0.54 \mathrm{k}+\mathrm{k}^{2} \\
\mathrm{~N}_{\mathrm{rr}}^{\prime}=\frac{0.5 \mathrm{C}_{\mathrm{b}} \mathrm{B}}{\mathrm{L}}-0.09 \\
\mathrm{~N}_{\beta \mathrm{rr}}^{\prime}=-\left(\frac{0.5 \mathrm{~d} \mathrm{C}_{\mathrm{b}}}{\mathrm{B}}-0.05\right) \\
\mathrm{N}_{\beta \beta \mathrm{r}}^{\prime}=-\left\{57.5\left(\frac{\mathrm{C}_{\mathrm{b}} \mathrm{B}}{\mathrm{L}}\right)^{2}-\frac{18.4 \mathrm{C}_{\mathrm{b}} \mathrm{B}}{\mathrm{L}}+1.6\right\} \\
1-\mathrm{t}_{\mathrm{R}}=0.28 \mathrm{C}_{\mathrm{b}}+0.55 \\
\mathrm{a}_{\mathrm{H}}=2.2835 \mathrm{C}_{\mathrm{b}}^{2}-0.833 \mathrm{C}_{\mathrm{b}} \\
\mathrm{x}_{\mathrm{H}}^{\prime}=9.72289 \mathrm{C}_{\mathrm{b}}^{2}-8.243538 \mathrm{C}_{\mathrm{b}}-0.00498539 \\
1-\mathrm{w}_{\mathrm{P} 0}=1.05-0.5 \mathrm{C}_{\mathrm{b}} \\
\gamma=-22.2\left(\mathrm{C}_{\mathrm{b}} \mathrm{B} / \mathrm{L}\right)^{2}+0.02\left(\mathrm{C}_{\mathrm{b}} \mathrm{B} / \mathrm{L}\right)+0.68
\end{gathered}
$$

As shown in Equation (7), it can be confirmed that the empirical formula contains parameters representing characteristics of hull form and that the feature parameters of each hull form in the process of deriving the empirical formula are correlated. In other words, when estimating the maneuverability of a vessel using the empirical formula, it can be inferred that estimation will be more accurate with low possibility of error if a vessel is similar to or has the same hull form as the vessel that was included in the model test.

\subsection{Modified Empirical Formula}

With most fishing vessels having a length $\left(\mathrm{L}_{\mathrm{BP}}\right)$ less than $100 \mathrm{~m}$, it is common to estimate manoeuvrability using empirical formulas rather than model tests during the design stage. For this reason, there was a limit to obtain the model test results in order to derive the empirical formula only for fishing vessel hull form. 
Therefore, considering these circumstances, the authors, performed a study for deriving a modified empirical formula for stern trawler hull form that had passed sea trial test and the design-phase test [18]. Here, the broad derivation process of the modified empirical formula is given by 1 to 3 below.

1. The model stern trawlers used to derive the modified empirical formula are five fisheries training vessels. These were selected because there existed the results of the sea trial test and the test at the design stage (resistance, self-propulsion, propelleropen water test) and it was possible to secure relatively accurate data. Table 1 below shows the main specifications of the five model stern trawlers (A-E) and Figure 2 shows the hull shape for each of the vessels shown in Table 1.

Table 1. Major specifications of model stern trawlers.

\begin{tabular}{ccccccc}
\hline & Scale & $\mathbf{C}_{\mathbf{b}}$ & $\mathbf{L}_{\mathbf{B P}}(\mathbf{m})$ & $\mathbf{B}(\mathbf{m})$ & $\mathbf{d}(\mathbf{m})$ & $\mathbf{L} / \mathbf{B}$ \\
\hline $\mathbf{A}$ & $1 / 20.833$ & 0.607 & 3.0 & 0.576 & 0.2112 & 5.208 \\
B & $1 / 20.2$ & 0.610 & 3.0 & 0.6089 & 0.2228 & 4.927 \\
C & $1 / 24.167$ & 0.574 & 3.0 & 0.5462 & 0.2069 & 5.492 \\
D & $1 / 28.333$ & 0.5872 & 3.0 & 0.5294 & 0.1835 & 5.667 \\
E & $1 / 28.333$ & 0.5923 & 3.0 & 0.5435 & 0.1871 & 5.520 \\
\hline
\end{tabular}

A

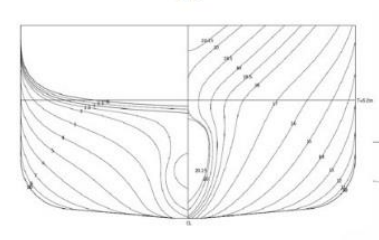

B

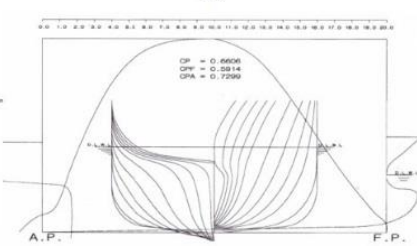

C

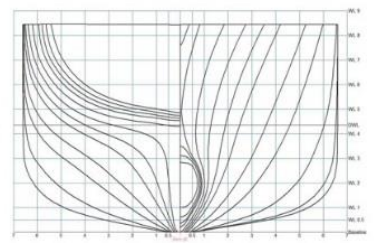

D

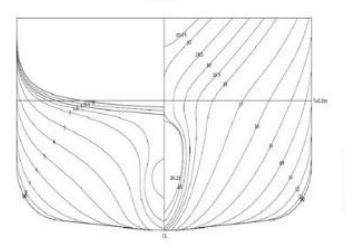

$\mathbf{E}$

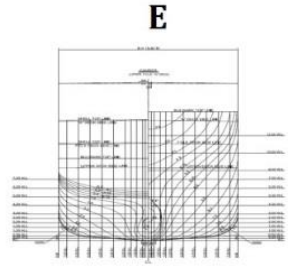

Figure 2. Body plans of model stern trawlers.

2. A comparison of $C_{b}$ relative to $L / B$ for 5 model stern trawlers and 13 merchant ships used for Kijima 90 empirical formula derivation to determine characteristics of hull form by ship type confirmed that as shown in Figure $3, C_{b}$ of the model stern trawlers that needs mobility as well as resilience was similar to that of the high-speed slender container, RORO, and car carrier and L/B was similar to that of low-speed larger ships like VLCC or ULCC.
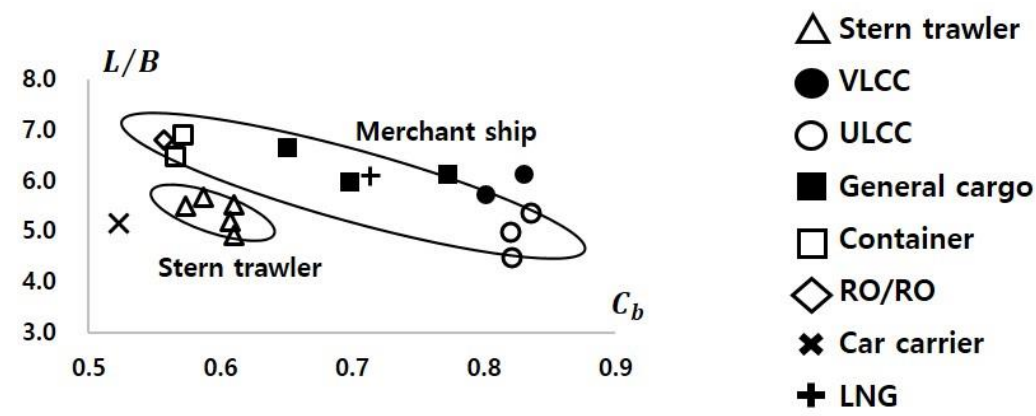

Figure $3 . C_{b}$ relative to $L / B$ of model ships.

3. From the above process, the model stern trawlers and common merchant ships were found to have distinct differences in hull-form characteristics, and it was determined that modification would be necessary to apply the empirical formula derived from the model test results of the merchant ships to the model stern trawlers. Therefore, using the Kijima 90 empirical formula, we derived the maneuvering-hydrodynamic coefficients of each vessel, and the modified empirical formula by correlating hull- 
form parameters with high correlation in the regression analysis. A typical correlation graph of hull-form coefficients is shown in Figure 4, and the modified empirical formula derived from this process can be represented as shown in Equation (8).

$$
\begin{gathered}
\mathrm{Y}_{\beta}^{\prime}=-1.5747 \times\left\{-\mathrm{C}_{\mathrm{b}} /(\mathrm{L} / \mathrm{B})\right\}+0.4488 \\
\mathrm{Y}_{\beta \beta}^{\prime}=0.0417 \times(\mathrm{L} / \mathrm{B})+0.541 \\
\mathrm{Y}_{\mathrm{r}}^{\prime}-\left(\mathrm{m} /+\mathrm{m}_{\mathrm{x}}^{\prime}\right)=0.0432 \times(\mathrm{L} / \mathrm{B})-0.4276 \\
\mathrm{Y}_{\mathrm{rr}}^{\prime}=-0.7946 \times\left\{1-\mathrm{C}_{\mathrm{b}} /(\mathrm{L} / \mathrm{B})\right\}+0.0563 \\
\mathrm{Y}_{\beta \mathrm{rr}}^{\prime}=0.0993 \times(\mathrm{L} / \mathrm{B})+0.0975 \\
\mathrm{Y}_{\beta \beta \mathrm{r}}^{\prime}=2.7467 \times \mathrm{k}-0.6316 \\
\mathrm{~N}_{\beta}^{\prime}=0.238 \times \mathrm{C}_{\mathrm{b}} /(\mathrm{B} / \mathrm{d})+0.0663 \\
\mathrm{~N}_{\beta \beta}^{\prime}=-0.016 \times(\mathrm{L} / \mathrm{B})+0.0503 \\
\mathrm{~N}_{\mathrm{r}}^{\prime}=0.0515 \times\left\{1-\mathrm{C}_{\mathrm{b}} /(\mathrm{L} / \mathrm{B})\right\}-0.0537 \\
\mathrm{~N}_{\mathrm{rr}}^{\prime}=-0.0144 \times(\mathrm{L} / \mathrm{B})+0.0525 \\
\mathrm{~N}_{\beta \mathrm{rr}}^{\prime}=-0.9156 \times \mathrm{k}+0.0439 \\
\mathrm{~N}_{\beta \beta \mathrm{r}}^{\prime}=-3.399 \times\left\{1-\mathrm{C}_{\mathrm{b}} /(\mathrm{L} / \mathrm{B})\right\}-0.0737 \\
1-\mathrm{t}_{\mathrm{R}}=-0.0127 \times(\mathrm{L} / \mathrm{B})+0.8122 \\
\mathrm{a}_{\mathrm{H}}=-0.1107 \times(\mathrm{L} / \mathrm{B})+1.1421 \\
\mathrm{x}_{\mathrm{H}}^{\prime}=-0.258 \times(\mathrm{L} / \mathrm{B})+0.4603 \\
1-\mathrm{w}_{\mathrm{P} 0}=0.0227 \times(\mathrm{L} / \mathrm{B})+0.5818 \\
\varepsilon=-1.4308 \times\left\{1-\mathrm{C}_{\mathrm{b}} /(\mathrm{L} / \mathrm{B})\right\}+0.9453 \\
\gamma=0.1608 \times(\mathrm{L} / \mathrm{B})-0.5764
\end{gathered}
$$
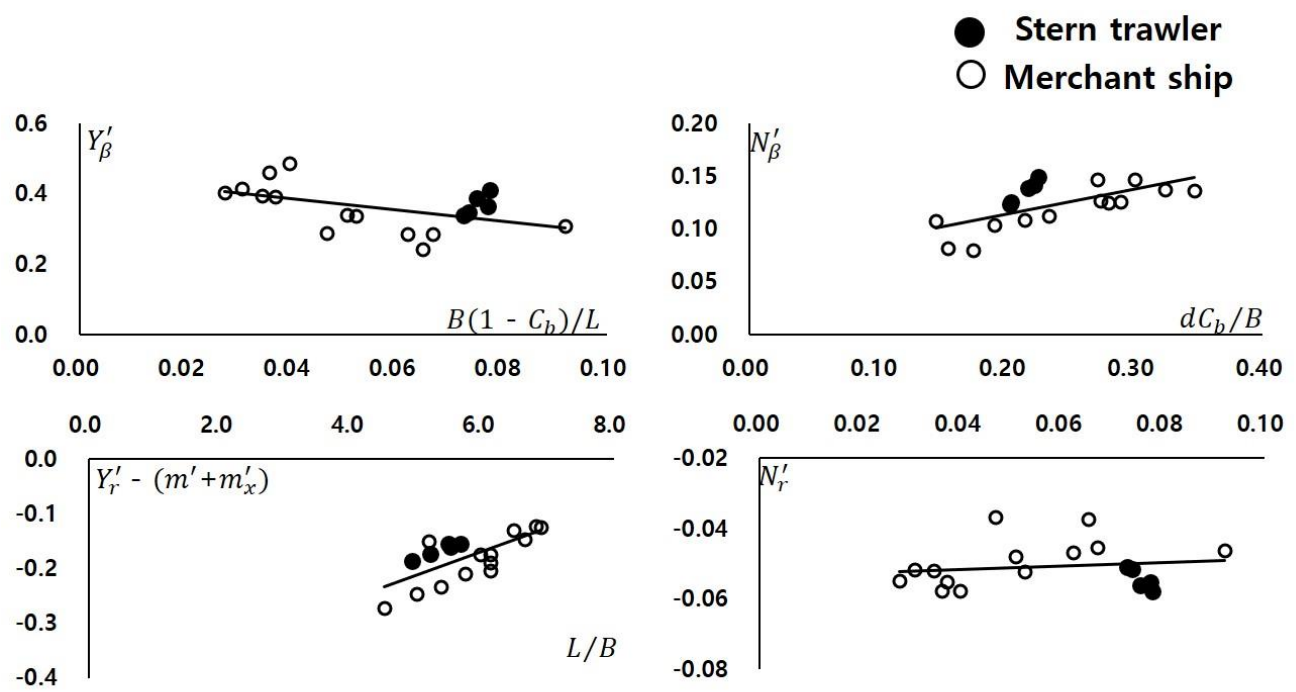

Figure 4. Correlation of linear coefficients and hull form characteristics in target ships.

\section{Verification of Effectiveness of Modified Empirical Formula}

The target fishing vessel used in this study was launched in October 2020 and all the sea trial tests have since been completed. The specifications of this vessel and its hull-form characteristics were included in the previous study to derive the modified empirical formula, however, it was in the construction phase at the time, so that study to verify the results of sea trial tests was not conducted [18]. Therefore, in this chapter, we derived maneuvering-hydrodynamic coefficients of the target fishing vessel using the modified empirical formula and Kijima 90 empirical formula, and performed verification by comparing 
with the results of the sea trial test. Also, all maneuvering-hydrodynamic coefficient values derived from the two empirical formulas have not been modified separately. The flow straightening coefficient $\gamma$ (known to be one of the most difficult to estimate interaction coefficients) and the effective wake coefficient $\mathrm{w}_{\mathrm{R} 0}$ at the rudder position were investigated separately in the following chapters.

The basic purpose of this study is to minimize the estimation errors that can occur in the empirical formula that is now widely used in the current fishing vessel design stage, and furthermore to check if including hull-form parameters of fishing vessels in the empirical formula developed for merchant ships can improve estimation accuracy.

\subsection{A Target Fishing Vessel}

A target fishing vessel used to verify the modified empirical formula is the fisheries training vessel of stern trawler type with $\mathrm{L}_{\mathrm{BP}} 85 \mathrm{~m}$. Figure 5 below is the body plan of the target fishing vessel. Table 2 represents the main specifications.

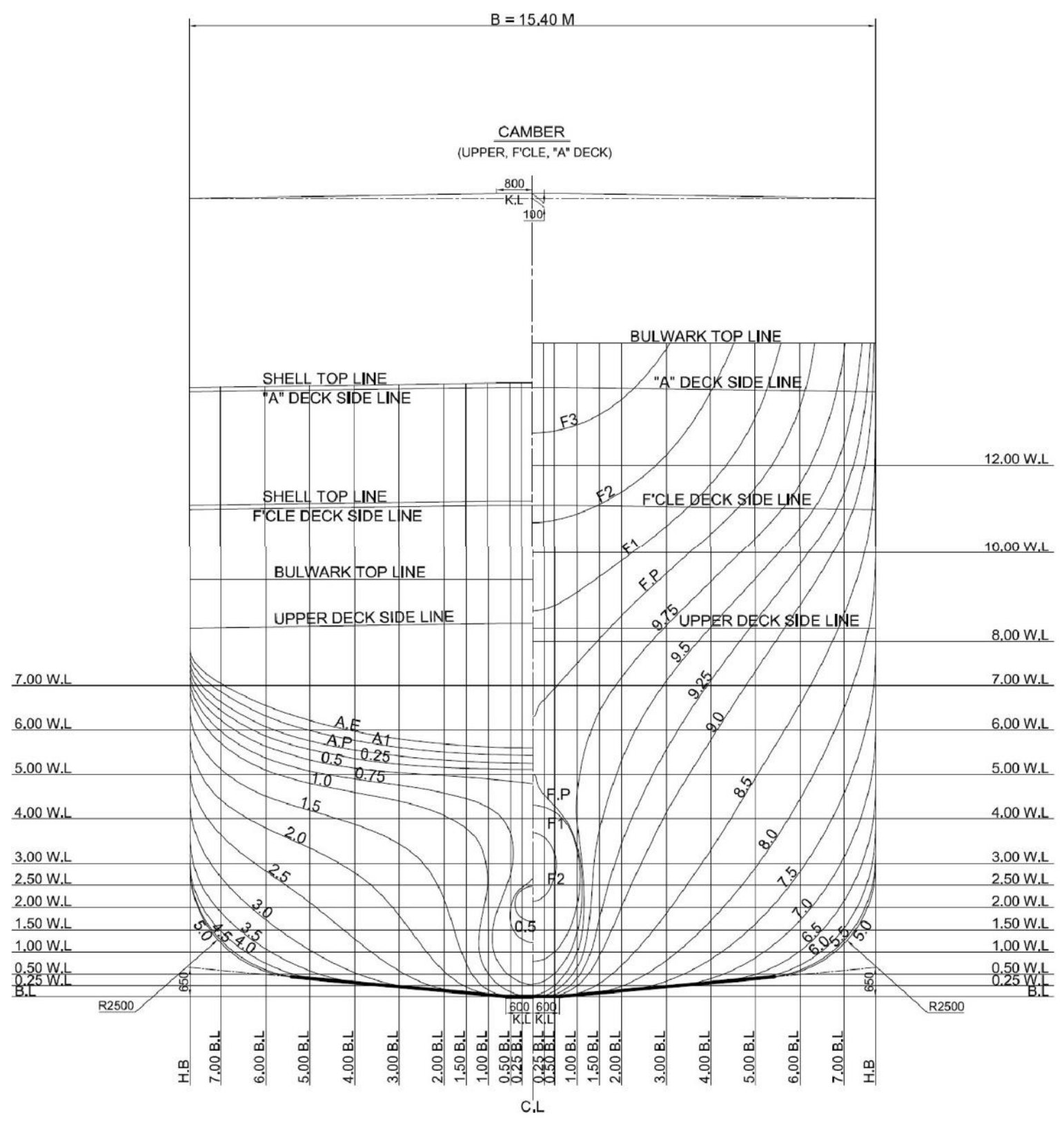

Figure 5. Body plan of target fishing vessel. 
Table 2. Major specifications of model stern trawlers.

\begin{tabular}{lccc}
\hline & & Type of Ship & \multicolumn{2}{c}{ Stern Trawler } \\
\cline { 3 - 4 } Specifications & & Model & Full Scale \\
\hline & Scale & $1 / 28.333$ & 1 \\
& $\mathrm{~L}_{\mathrm{BP}}(\mathrm{m})$ & 3.0 & 85.0 \\
& $\mathrm{~B}(\mathrm{~m})$ & 0.5435 & 15.4 \\
& $\mathrm{~d}(\mathrm{~m})$ & 0.1871 & 5.3 \\
$\mathrm{C}_{\mathrm{b}}$ & & 0.5923 & \\
\hline
\end{tabular}

\subsection{A Derivation of Manoeuvring-Hydrodynamic Coefficients}

The maneuvering-hydrodynamic coefficients obtained from the empirical formula can be largely divided into forces acting on a hull and interaction forces acting between hulls, propellers, and rudders. However, as stated above, the accuracy of the estimation may vary depending on the difference in hull form, because hull-form parameters have a large correlation in the empirical formula derivation process. In other words, the accuracy of estimation may be high when the hull form is the same as or similar to that involved in model tests for deriving an empirical formula and the accuracy for dissimilar hull form, such as fishing vessels, may be low. In particular, these interaction coefficients are very difficult and complex to estimate at the design stage, so they are estimated by considering the unique characteristics of the same or a similar hull form [15].

However, the fundamental purpose of this study is to verify the validity of the improvement of the accuracy of estimating the maneuverability of fishing vessel hull form by modifying the empirical formula developed for merchant ship hull form. Thus, the value of the interaction coefficients derived from the empirical formula was also applied without modification according to the unique characteristic of the target fishing vessel.

Table 3 below shows the value of the maneuvering-hydrodynamic coefficients of the target fishing vessel derived from the Kijima 90 empirical formula (Equation (7)) and the modified empirical formula (Equation (8)).

Table 3. Comparison of maneuvering-hydrodynamic coefficients.

\begin{tabular}{cccc}
\hline & Hydrodynamic Coefficients & Kijima 90 Formula & Modified Formula \\
\hline & $\mathrm{Y}_{\beta}^{\prime}$ & 0.34605836 & 0.33249006 \\
$\mathrm{Y}_{\beta \beta}^{\prime}$ & 0.85087705 & 0.77117479 \\
$\mathrm{Y}_{\mathrm{r}}^{\prime}-\left(\mathrm{m}^{\prime}+\mathrm{m}_{\mathrm{x}}^{\prime}\right)$ & -0.16095753 & -0.18914554 \\
$\mathrm{Y}_{\mathrm{rr}}^{\prime}$ & -0.00006250 & -0.00239047 \\
$\mathrm{Y}_{\beta \mathrm{rr}}^{\prime}$ & 0.83508737 & 0.64561408 \\
$\mathrm{Y}_{\beta \beta \mathrm{r}}^{\prime}$ & -0.34415088 & -0.28899495 \\
$\mathrm{~N}_{\beta}^{\prime}$ & 0.12473333 & 0.11482806 \\
$\mathrm{~N}_{\beta \beta}^{\prime}$ & -0.06873679 & -0.03801647 \\
$\mathrm{~N}_{\mathrm{r}}^{\prime}$ & -0.05179760 & -0.04989613 \\
$\mathrm{~N}_{\mathrm{rr}}^{\prime}$ & -0.03634749 & -0.02698482 \\
$\mathrm{~N}_{\beta \mathrm{rr}}^{\prime}$ & -0.05194971 & -0.07030584 \\
$\mathrm{~N}_{\beta \beta \mathrm{r}}^{\prime}$ & -0.28766377 & -0.32475575 \\
$1-\mathrm{t}_{\mathrm{R}}$ & 0.71584400 & 0.74209880 \\
$\mathrm{a}_{\mathrm{H}}$ & 0.30770995 & 0.53106044 \\
\hline $\mathrm{x}_{\mathrm{H}}^{\prime}$ & -1.47665558 & -0.96380304 \\
$\mathrm{w}_{\mathrm{P} 0}$ & 0.24615000 & 0.29290101 \\
$\mathrm{w}_{\mathrm{R} 0}$ & 0.31750595 & 0.40630643 \\
$\varepsilon$ & 0.90534463 & 0.83961875 \\
& $\gamma$ & 0.42652716 & 0.31118050 \\
\hline
\end{tabular}




\subsection{Comparison of Turning Motion}

The following conditions are required for performing a maneuverability evaluation [1].

- Deep, unrestricted water

- Calm environment

- Full load, even keel condition

- Steady approach at the test speed

However, it is not easy to completely match all of these conditions, and it is common to set them as close as possible. The sea trial test of the target fishing vessel was also carried out under as similar conditions as possible, although it did not perfectly match the above conditions. On the other hand, simulations performed from modified empirical formulas were based on the assumption that they match the conditions presented in the IMO maneuverability criteria.

Differences in these conditions may have a slight effect on the results of the verification, but the authors have already obtained the coefficient values in the design conditions for the target fishing vessel through previous studies, so those values were used as is to prevent possible misunderstanding that may occur due to modification. Here, the simulation conditions of the target fishing vessel and the conditions of the sea trial test are as shown in Table 4.

Table 4. Turning motion conditions.

\begin{tabular}{ccc}
\hline & Sea Trial Test Condition & $\begin{array}{c}\text { Empirical Formula Condition } \\
\text { (Kijima 90, Modified) }\end{array}$ \\
\hline Wind direction (Relative) \& & PORT: $205^{\circ}, 3.8 \mathrm{~m} / \mathrm{s}$ & calm \\
Speed & STBD: $206^{\circ}, 4.1 \mathrm{~m} / \mathrm{s}$ & $\mathrm{h} / \mathrm{d}>6$ \\
Water depth & h/d $>$ 6 (approx. $130 \mathrm{~m})$ & FWD: 5.3 \\
Ship draft $(\mathrm{m})$ & FWD: 5.18 & AFT: 5.3 \\
& AFT: 5.28 & PORT: 14.04 \\
Test speed $(\mathrm{kts})$ & PORT: 14.2 & STBD: 14.04 \\
\hline
\end{tabular}

As a result of checking the turning motion trajectory, as shown in Table 5, both the results of Kijima 90 empirical formula and the modified empirical formula satisfied the IMO maneuverability criteria.

Table 5. Turning motion conditions.

\begin{tabular}{lccccc}
\hline & Sea Trial Test & $\begin{array}{c}\text { Kijima 90 } \\
\text { Formula }\end{array}$ & $\begin{array}{c}\text { Modified } \\
\text { Formula }\end{array}$ & IMO Criteria \\
\hline \multirow{4}{*}{ Advance $(m)$} & PORT & $241(2.8 \mathrm{~L})$ & $272(3.2 \mathrm{~L})$ & $224(2.6 \mathrm{~L})$ & \\
& STBD & $212(2.5 \mathrm{~L})$ & $277(3.3 \mathrm{~L})$ & $229(2.7 \mathrm{~L})$ & $<383(4.5 \mathrm{~L})$ \\
& Average & $227(2.7 \mathrm{~L})$ & $275(3.2 \mathrm{~L})$ & $227(2.7 \mathrm{~L})$ & \\
\hline \multirow{5}{*}{ Tac. Dia. $(\mathrm{m})$} & PORT & $225(2.6 \mathrm{~L})$ & $330(3.9 \mathrm{~L})$ & $250(2.9 \mathrm{~L})$ & \\
& STBD & $245(2.9 \mathrm{~L})$ & $343(4.0 \mathrm{~L})$ & $260(3.0 \mathrm{~L})$ & $<425(5.0 \mathrm{~L})$ \\
& Average & $235(2.8 \mathrm{~L})$ & $337(4.0 \mathrm{~L})$ & $255(3.0 \mathrm{~L})$ & \\
\hline
\end{tabular}

Firstly, compared to the sea trial test, the Kijima 90 empirical formula showed the advance having an average error of $0.5 \mathrm{~L}$ bigger and the tactical diameter having an average error of $1.2 \mathrm{~L}$ increase. On the other hand, the modified empirical formula showed the average of advance the same as the results of the sea trial test and the average of tactical diameter showed $0.2 \mathrm{~L}$ increase of error.

From this result and the results of previous studies, it has been confirmed that modifying the empirical formula developed for merchant ships by incorporating hull-form parameters of fishing vessels alone can improve the results. 
However, as seen in Figure 6 by referring to Table 4 , in the case of the sea trial test, the results of the turning motion trajectory of the port and starboard are somewhat different from the nature of the trajectory represented by the simulation, as the sea trial test was affected by external forces such as wind force. When only wind blowing from the direction of the stern on the port side is considered simply without lateral pressure, due to the wind blowing from relative wind direction (approx. $206^{\circ}$ ), the trajectory may be smaller than the standard in the case of a port turn, and greater than the standard in the case of a starboard turn.

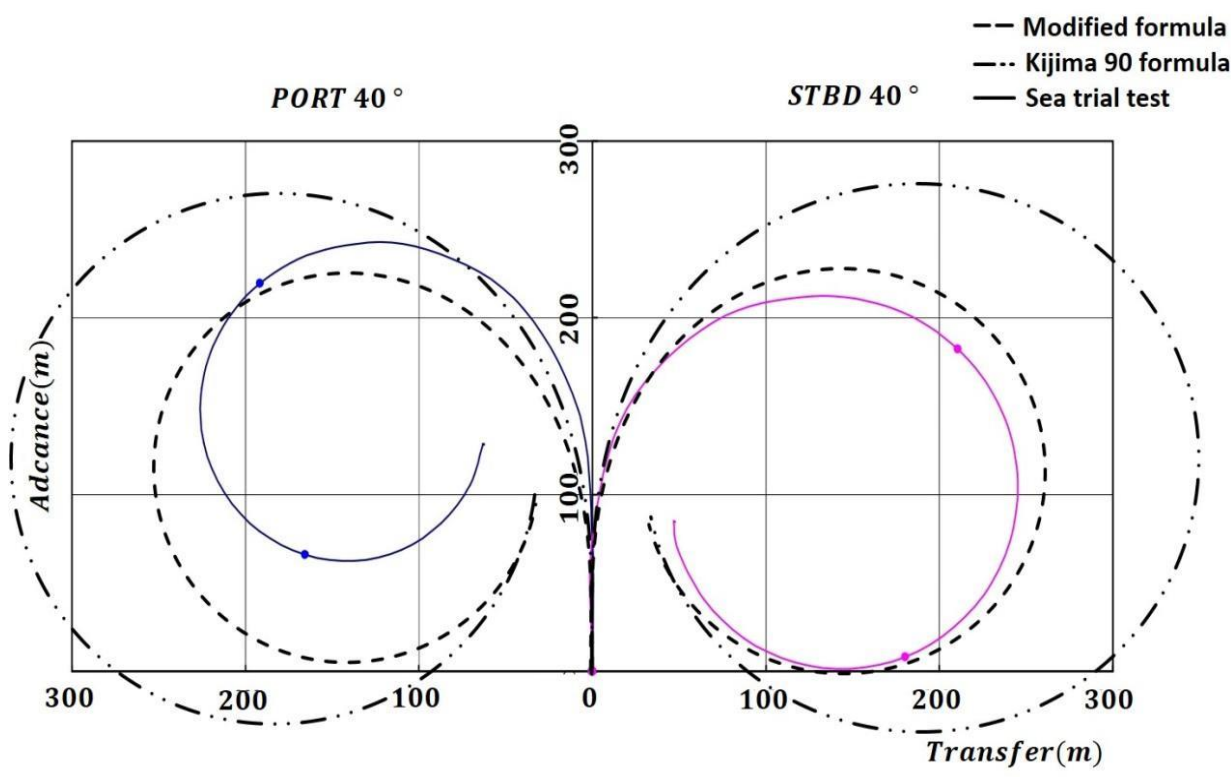

Figure 6. Comparison of turning motion trajectory.

In these results, the starboard-turn trajectory from the modified empirical formula was approximately the same as the trajectory from the sea trial test, but in reality it will be slightly greater than that represented in the figure. In the same vein, in the case of a port-turn trajectory, the estimation error is expected to differ slightly more than the values shown in Table 4.

\subsection{Study on the Interaction Coefficient}

In the process of deriving an empirical formula, the hull-form parameters such as $\mathrm{L} / \mathrm{B}$ or $\mathrm{C}_{\mathrm{b}} /(\mathrm{L} / \mathrm{B})$ are highly correlated; hence, the accuracy of the maneuverability estimation may vary depending on hull forms. Above all, the interaction coefficients between the hull, propeller, and rudder are the most difficult and complex to estimate during the design phase, so its estimation in the design phase is completed considering the characteristics of the same or similar hull forms to enhance the estimation accuracy [15]. In particular, it is not easy to estimate the flow straightening coefficient $\gamma$ or effective wake coefficient $\mathrm{w}_{\mathrm{R} 0}$ at the rudder location during the design stage despite their importance in the maneuvering characteristics.

Based on this, Figure 7 shows the turning motion trajectory of the target fishing vessel according to the flow straightening coefficient $\gamma$ and the effective wake coefficient $\mathrm{w}_{\mathrm{R} 0}$ at the rudder location. The value shown in the solid line is a trajectory under standard conditions. As shown in the figure, it can be seen that the straightening coefficient $\gamma$ affects the ship's advance and the tactical diameter simultaneously and that the effective wake coefficient $\mathrm{w}_{\mathrm{R} 0}$ at the rudder location mainly affects the advance. In particular, it can be seen that during steady turning motion, the straightening coefficient $\gamma$ is correlated with the normal pressure acting on rudder $F_{N}^{\prime}[15]$ as shown in Equation (6). In fishing vessels with large rudder area ratios compared to common merchant ships, these characteristics 
should particularly be taken into account for construction purposes because the rudder area ratio is directly related to the normal pressure $\mathrm{F}_{\mathrm{N}}^{\prime}$ [24].

(a)

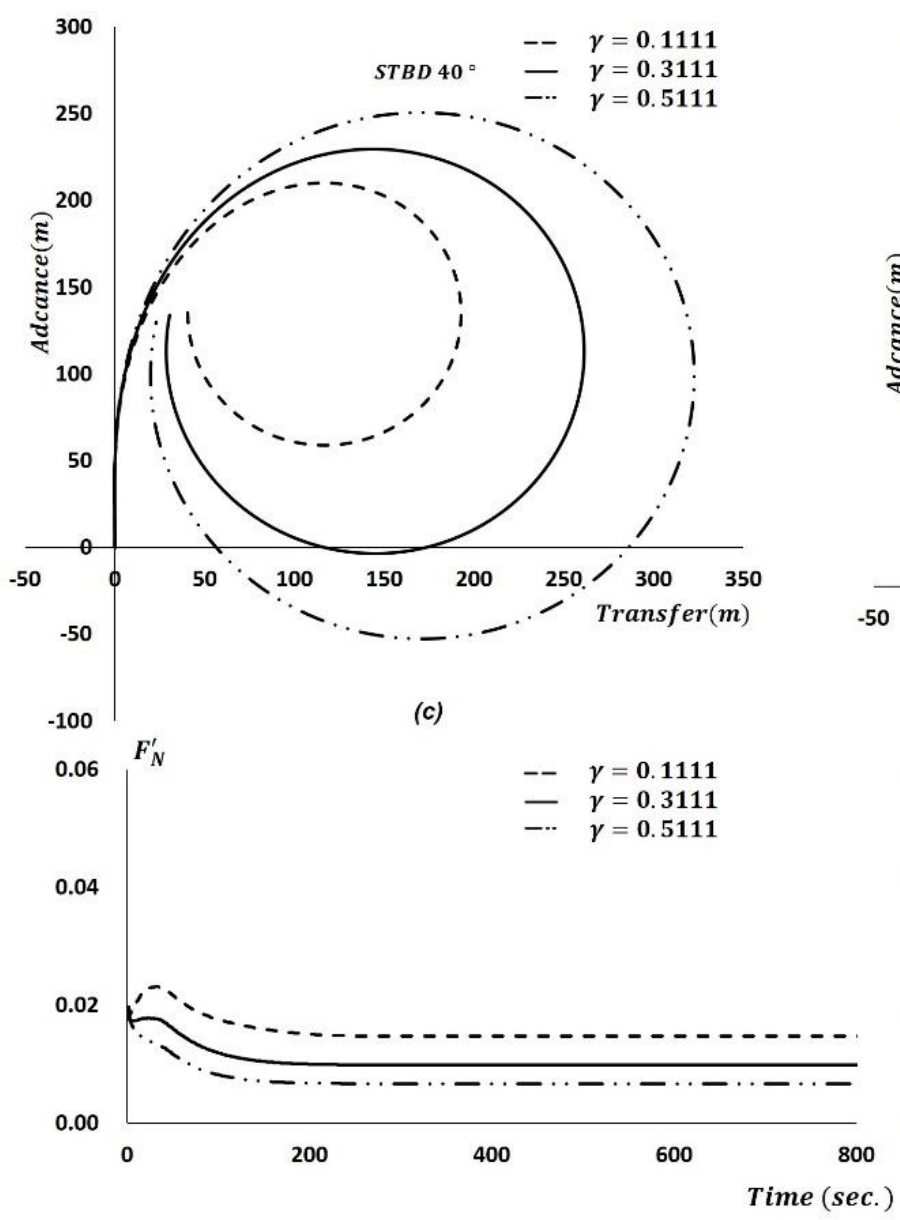

(b)

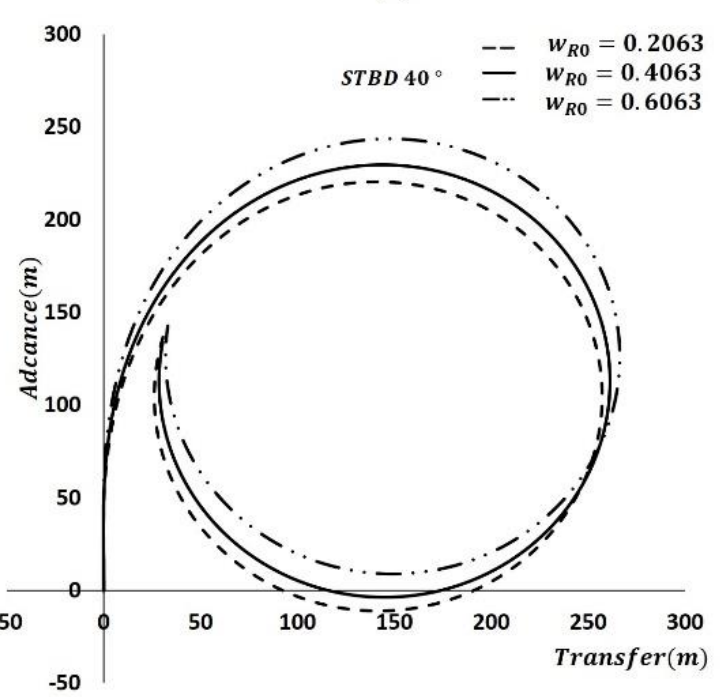

(d)

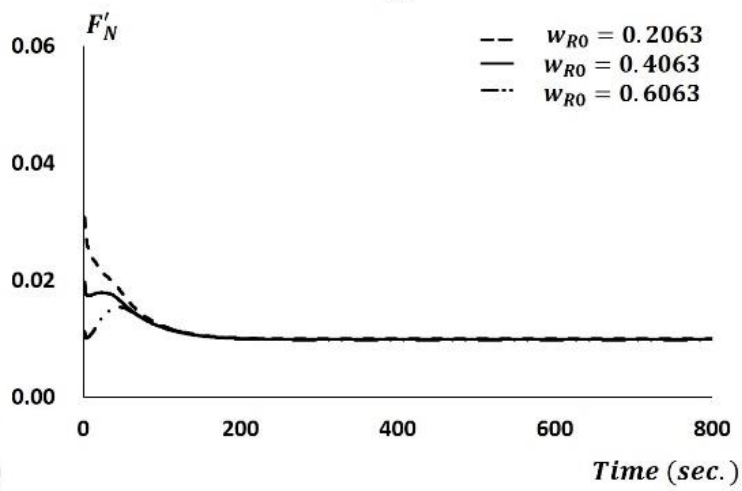

Figure 7. Comparisons of (a) and (b) turning characteristics depending on the variation of $\gamma(\mathbf{c})$ and $\mathrm{w}_{\mathrm{R} 0}(\mathbf{d})$ interaction coefficients.

\section{Conclusions}

Most fishing vessels are not required to comply with the IMO criteria; therefore, there is a lack of research which estimates maneuverability in comparison with merchant ships. In the fishing industry, there are many people aboard fishing vessels and any collision or stranding accident related to errors in maneuvering can lead to casualties [11,14]. Therefore, regardless of whether the IMO criteria are applicable, studies on estimating maneuverability according to the design stage and situation need to be conducted.

From this perspective, this study has derived the maneuvering-hydrodynamic coefficients of the target fishing vessel, using the modified empirical formula and Kijima 90 empirical formula, and verified its effectiveness by comparing with the results of sea trial tests.

As a result of the turning motion trajectory, both results satisfied the IMO maneuverability criteria. Compared to the sea trial test, the Kijima 90 empirical formula showed the advance having an average error increase of $0.5 \mathrm{~L}$ and the tactical diameter having an average error increase of $1.2 \mathrm{~L}$. On the other hand, the modified empirical formula showed that the average of advance was the same as the results of the sea trial test and the average of tactical diameter showed $0.2 \mathrm{~L}$ increase of error.

From this result, it was found that the modified empirical formula was more accurate than the Kijima 90 empirical formula in estimating maneuverability of trawler hull form, and although there were minor differences in external forces, it is noteworthy that the 
accuracy of the estimation can be improved by including feature parameters of the trawler hull form in the Kijima 90 empirical formula developed for merchant ships.

Research like this on the design-phase data (resistance, self-propulsion, propeller-open water test) of different kinds of fishing vessels, hull-form coefficients, characteristics of unique interaction coefficients, etc. will further improve the estimation of fishing vessel maneuverability in the design phase of a shipyard. Furthermore, there is also a possibility of developing an approximating formula, which is mainly targeted toward fishing vessel hull forms in the future. In addition, such research will enable simulation that can recreate the conditions of a fishing vessel maneuvering accident. This will be helpful in the ongoing research of autonomous vessels while also providing more reliable fishing vessel hullform parameters.

Author Contributions: Conceptualization, S.-M.L.; methodology, S.-H.K.; software, C.-K.L.; analysis, S.-H.K.; writing—original draft preparation, S.-H.K.; writing—reviewing and editing, C.-K.L.; supervision, S.-H.K. Author has read and agreed to the published version of the manuscript.

Funding: This research received no external funding.

Institutional Review Board Statement: Not applicable.

Informed Consent Statement: Not applicable.

Data Availability Statement: The data used to support the findings of this study are available from the corresponding author upon request.

Acknowledgments: This research was supported by the 'Development of Autonomous Ship Technology (20200615) 'funded by the Ministry of Oceans and Fisheries (MOF, Korea).

Conflicts of Interest: The authors declare no conflict of interest.

\section{Nomenclature}

\begin{tabular}{|c|c|}
\hline$A_{R}$ & rudder area \\
\hline $\mathrm{a}_{\mathrm{H}}$ & rudder force increase factor \\
\hline $\mathrm{C}$ & coefficient for starboard and port rudder \\
\hline $\mathrm{C}_{\mathrm{N}}$ & rudder normal force gradient coefficient \\
\hline $\mathrm{C}_{\mathrm{tP}}$ & constants \\
\hline$C_{1}, C_{2}, C_{3}$ & constants \\
\hline $\mathrm{D}_{\mathrm{P}}$ & propeller diameter \\
\hline $\mathrm{F}_{\mathrm{N}}^{\prime}$ & normal force acting on the rudder/non-dimensionalized \\
\hline $\mathrm{h}_{\mathrm{R}}$ & rudder height \\
\hline$I_{z z}^{\prime}, i_{z z}^{\prime}$ & inertia moment of $z$ axis direction, added inertia moment/non-dimensionalized \\
\hline $\mathrm{J}_{\mathrm{P}}$ & advance coefficient \\
\hline $\mathrm{K}_{\mathrm{R}}$ & aspect ratio of the rudder \\
\hline $\mathrm{K}_{\mathrm{T}}$ & thrust coefficient \\
\hline $\mathrm{m} /, \mathrm{m}_{\mathrm{x}}^{\prime}, \mathrm{m}_{\mathrm{y}}^{\prime}$ & mass of ship, added mass of $x$ axis \\
\hline & direction, added mass of y axis direction/non-dimensionalized \\
\hline $\mathrm{n}$ & propeller revolution \\
\hline $\mathrm{nP}$ & propeller revolution \\
\hline S & slip ratio \\
\hline$t_{\mathrm{P} 0}$ & thrust deduction coefficient in straight forward moving direction \\
\hline$t_{R}$ & steering deduction factor \\
\hline $\mathrm{U}, \beta, \delta$ & resultant velocity, drift angle, rudder angle \\
\hline $\mathrm{U}_{\mathrm{R}}$ & effective rudder inflow speed \\
\hline $\mathrm{u}, \mathrm{v}, \mathrm{r}$ & velocity components at the center of gravity of ship \\
\hline $\mathrm{w}_{\mathrm{P}}$ & effective wake coefficient at the position of the propeller \\
\hline $\mathrm{w}_{\mathrm{R}}$ & effective wake coefficient at the position of the rudder \\
\hline
\end{tabular}




\begin{tabular}{|c|c|}
\hline $\mathrm{w}_{\mathrm{P} 0}$ & $\begin{array}{l}\text { effective wake coefficient at the position of the propeller in straight } \\
\text { forward moving direction }\end{array}$ \\
\hline $\mathrm{w}_{\mathrm{R} 0}$ & $\begin{array}{l}\text { effective wake coefficient at the position of the rudder in straight } \\
\text { forward moving direction }\end{array}$ \\
\hline$x_{H}^{\prime}$ & $\begin{array}{l}\text { distance between C.G and the center of additional lateral } \\
\text { force/non-dimensionalized }\end{array}$ \\
\hline$x_{R}^{\prime}$ & longitudinal coordinate of the position of the rudder/non-dimensionalized \\
\hline$a_{R}$ & effective rudder inflow angle \\
\hline$\beta_{\mathrm{R}}^{\prime}$ & $\begin{array}{l}\text { effective inflow angle to the rudder in maneuvering } \\
\text { motion/non-dimensionalized }\end{array}$ \\
\hline$\delta$ & rudder angle \\
\hline $\mathrm{k}$ & $2 d / L$ \\
\hline$\gamma$ & flow straightening coefficient \\
\hline $1-\mathrm{w}_{\mathrm{P}}$ & effective wake fraction at the position of the propeller \\
\hline$\cdot(\operatorname{dot})$ & derivative with respect to time \\
\hline ' (prime) & non-dimensionalized quantity \\
\hline
\end{tabular}

\section{References}

1. IMO MSC 76/23. Standards for Ship Manoeuvrability" Report of the Maritime Safety Committee on Its 76th Session-Annex 6. Resolut. MSC 2002, 137, 1-6.

2. Kim, K.Y. Manoeuverabilities of the M.S “SAEBADA". J. Korean Soc. Fish. Ocean Technol. 1979, 12, $209-215$.

3. Kim, M.S.; Shin, H.O.; Kang, K.M.; Kim, M.S. Variation of Turning Circle by the Rudder Angle and the Ship's Speed. J. Korean Soc. Fish. Ocean Technol. 2005, 41, 156-164. [CrossRef]

4. Ahn, Y.H.; Park, M.H.; Choi, C.M.; Chung, Y.J. A Study on the Maneuverabilities of the Training ship M.S. A-RA. J. Korean Soc. Fish. Ocean Technol. 2001, 37, 275-284.

5. An, Y.S.; Kang, I.K.; Kim, H.S.; Kim, J.C.; Kim, M.S.; Jo, H.J.; Lee, C.K. A Study on the Manoeuvrability of T/S SAEBADA by Real sea trials. J. Korean Soc. Fish. Ocean Technol. 2005, 41, 289-295. [CrossRef]

6. Kim, M.S.; Shin, H.I.; Kim, J.H.; Kang, I.K. A Study on the Maneuverabilities of the T.S KAYA. J. Fish. Mar. Sci. Educ. 2009, 21,59-67.

7. Yoshimura, Y.; Ma, N.; Suzuki, S.; Kajiwara, Y. Manoeuvring Performance of the Fishing Boat Modified by a Bulge. J. Soc. Nav. Archit. Jpn. 2002, 192, 37-46. [CrossRef]

8. Yoshimura, Y.; Ma, N. Manoeuvring Prediction of Fishing vessel. In MARSIM 03'Conference Proceedings; The Society of Naval Architects of Japan, Japan Institute of Navigation and International Marine Simulator Forum: Kanazawa, Japan, 2003.

9. Obreja, D.; Nabergoj, R.; Crudu, L.; Păcuraru-Popoiu, S. Identification of hydrodynamic coefficients for manoeuvring simulation model of a fishing vessel. Ocean Eng. 2010, 37, 678-687. [CrossRef]

10. Yoshimura, Y.; Masumoto, Y. Hydrodynamic force with medium high speed merchant ships including fishing vessels and investigation into a manoeuvring prediction method. J. Jpn. Soc. Nav. Archit. Ocean Eng. 2011, 14, 63-73. [CrossRef]

11. Lee, M.K.; Park, Y.S. Collision Prevention Algorithm for Fishing Vessels Using WAVE Communication. J. Mar. Sci. Eng. 2020, 8, 115. [CrossRef]

12. Jung, C.H. A Study on the Improvement of Safety by Accidents Analysis of Fishing Vessels. J. Fish. Mar. Sci. Educ. 2018, 30, 179-186.

13. Kim, S.H.; Kim, H.S.; Lee, Y.W. The causes and counterplan for marine casualties of fishing boats according to the fishing types. J. Korean Soc. Fish. Ocean Technol. 2020, 56, 246-257. [CrossRef]

14. Lee, M.K.; Park, Y.S.; Park, S.W.; Lee, E.K.; Park, M.J.; Kim, N.E. Application of Collision Warning Algorithm Alarm in Fishing Vessel's Waterway. Appl. Sci. 2021, 11, 4479. [CrossRef]

15. Kijima, K.; Katsuno, T.; Nakiri, Y.; Furukawa, Y. On the manoeuvring performance of a ship with the parameter of loading condition. J. Soc. Nav. Archit. Jpn. 1990, 168, 141-148. [CrossRef]

16. Lee, C.K.; Kim, S.H.; Lee, J.G.; Lee, S.M.; Kim, M.S. A study on the characteristics of manoeuvrability of fishing vessel. J. Korean Soc. Fish. Ocean Technol. 2018, 54, 239-245. [CrossRef]

17. Lee, C.K.; Kim, S.H.; Yim, J.B.; Lee, S.M. Study on the maneuvering characteristics of a fishing vessel in shallow water. Nav. Eng. J. 2019, 131-132, 95-104.

18. Kim, S.H. A Study on the Improvement of the Accuracy of Fishing Vessels Manoeuvrability Prediction. Ph.D. Thesis, Korea Maritime and Ocean University, Busan, Korea, 2020.

19. Ogawa, A.; Koyama, T.; Kijima, K. MMG report-I, on the mathematical model of ship manoeuvring. Bull. Soc. Nav. Archit. Jpn. 1977, 575, 22-28.

20. Yoshimura, Y.; Yasukawa, H. Introduction of MMG standard method for ship maneuvering predictions. J. Mar. Sci. Technol. 2015, 20, 37-52. [CrossRef]

21. Kobayashi, E.; Kagemoto, H.; Furukawa, Y. Mathematical Models of Ship Manoeuvring Motion; 2nd Symposium; The Japan Society of Naval Architects: Tokyo, Japan, 1995; pp. 23-84. 
22. Kijima, K.; Nakiri, Y. Approximate expression for hydrodynamic derivatives of ship manoeuvring motion taking into account of the effect of stern shape. Trans. West Jpn. Soc. Nav. Arch. 1999, 98, 67-77.

23. Kijima, K.; Nakiri, Y. On the practical prediction method for ship manoeuvring characteristics. Trans. West Jpn. Soc. Nav. Arch. 2003, 105, 21-31.

24. Yoon, J.D. Theory and Practice of Ship Manoeuvring; Sejong Publishing Co.: Busan, Korea, 2019. 